\title{
Lusioersily
}

\section{Exploring the accessibility of sport stadia for people with disability: Towards the development of a Stadium Accessibility Scale (SAS)}

Kitchin, P. J., Paramio-Salcines, J. L., Darcy, S., \& Walters, G. (2022). Exploring the accessibility of sport stadia for people with disability: Towards the development of a Stadium Accessibility Scale (SAS). Sport, Business, Management: An International Journal, 12(1), 93-116. https://doi.org/10.1108/SBM-05-2021-0064

Link to publication record in Ulster University Research Portal

Published in:

Sport, Business, Management: An International Journal

Publication Status:

Published (in print/issue): 25/02/2022

DOI:

https://doi.org/10.1108/SBM-05-2021-0064

\section{Document Version}

Author Accepted version

\section{General rights}

Copyright for the publications made accessible via Ulster University's Research Portal is retained by the author(s) and / or other copyright owners and it is a condition of accessing these publications that users recognise and abide by the legal requirements associated with these rights.

\section{Take down policy}

The Research Portal is Ulster University's institutional repository that provides access to Ulster's research outputs. Every effort has been made to ensure that content in the Research Portal does not infringe any person's rights, or applicable UK laws. If you discover content in the Research Portal that you believe breaches copyright or violates any law, please contact pure-support@ulster.ac.uk. 
Exploring the accessibility of sport stadia for people with disability: Towards the development of a Stadium Accessibility Scale (SAS)

Accepted for publication in Sport, Business, Management: An International Journal

\begin{abstract}
Purpose: The aim of this paper is to synthesise existing literature on sports stadia, spectators with disabilities (SwD), and accessibility to identify themes and to highlight the gaps in the literature. This review subsequently develops two propositions that will enable research in this emerging area to further develop.
\end{abstract}

Design/methodology/approach: The research was guided by two research questions: first, what does the peer reviewed evidence tell us about spectators with disability (SwD) and the accessibility of sporting stadia? Second, how can this information be used to develop a Stadium Accessibility Scale (SAS)? The authors conducted a rapid review of the literature across three databases that identified 34 papers for synthesis.

Findings: Synthesis revealed three research themes: a focus on legislative compliance, the need to enhance resources (both physical and human); and research that focuses on moving beyond the stadium experience. The latter can be sub-divided into two streams - studies that look at accessibility as a social legacy of major events, and studies that seek to understand the whole journey that SwD's must make to attend sport events.

Research limitations/implications: The study makes two key recommendations. The first is to encourage further research aligned to the HOPES framework (Paramio-Salcines et al., 2018) that explicitly recognises the importance of understanding the broader approach to the customer experience. The second is the need for the development and validation of a reliable SAS.

Social Implications: Greater accessibility provides a foundation for inclusive environments in sport. The findings are relevant for all stakeholders in sport as universal accessibility benefits more than people with disabilities.

Key words: Accessibility, Disability, Social model of disability, Inclusion, Sport Stadia, Stadium Accessibility Scale

\title{
Research Paper
}

Accepted pre-proofed manuscript by SMB editorial office 19-Nov-2021 


\section{Exploring the accessibility of sport stadia for people with disability: Towards the development of a Stadium Accessibility Scale (SAS)}

\section{Introduction}

In recent years, requirements for universal accessibility and inclusion within stadia, particularly in professional football, have risen to the forefront of the political and publicprivate debate, notably in Australia/New Zealand, Britain and the United States (Australian Human Rights Commission (AHRC), 2021; Culture, Media, and Sport Select Committee, 2016, 2017; Equality and Human Rights Commission (EHRC), 2017; Hums et al., 2016). These political, economic, legal, demographic, and social processes can be seen within the context of broader political and social pressures to ensure that disabled people have access to community and social life. In 2017, the Equality and Human Rights Commission (EHRC) highlighted some of the stark issues facing disabled people over the years. According to the Chair of the EHRC, David Isaac, (EHRC, 2017, p. 5) people with disabilities (PwD) "are still being treated as second-class citizens. Progress to date is not sufficient, and the road to disability equality is littered with missed opportunities and failures".

The broader focus on accessibility has transcended into professional sport and major events. Many event holders and National Sports Organizations (NSOs) are increasingly faced with having to demonstrate societal legitimacy and credibility to the "new generation of sport consumers' such as those with disabilities and older adults (García, 2017; Paramio-Salcines and Llopis-Goig, 2019). These pressures come from a range of sources, including governments, international and national football governing bodies, advocacy groups, and the media (Kitchin et al., 2019), and impact on meso-level organisational policies and practices of sports organisations. For example, in professional football, these pressures have contributed to modify the approach of one of the world's richest sporting leagues, the English Premier League (EPL) clubs and their efforts to augment inclusion and accessibility at their stadia for supporters with disabilities (SwD). As David Isaac highlighted before, it is still the case that addressing the needs and expectations of SwD is considered a luxury offering from some EPL clubs' stadia (EHRC, 2017).

While academic interest in sport and its accessibility for PwD has gained more managerial and legal interest for both academics and any professional involved in the sport industry in recent years, it was only recently that Paramio-Salcines and Kitchin (2013) introduced these 
notions of accessible tourism (Buhalis and Darcy, 2011) into the sport management literature. In the eight years since their study, the number of publications on this topic has increased steadily (Darcy et al., 2017). As such, the aim of this paper is to review the literature on SwD, stadia and accessibility from not just sport management, but across wider social scientific studies with the goal of synthesising a series of major themes. To achieve this aim, we ask two questions:

1. What does the peer reviewed evidence tell us about SwD and the accessibility of sporting stadia?

2. How can this information develop propositions for assessing a Stadium Accessibility Scale (SAS)?

From these findings we seek to highlight the gaps in the literature and to address these, we will develop propositions for further development in research and practice. These propositions will call for future research to explore accessibility, not just at the stadium where the event is held, but also to develop a holistic sequenced approach for sport managers to conceptualise the entire journey an athlete, official, employee or spectator may be required to make. We argue that it is this broader understanding of disability, access and inclusion that sport managers require if we are to be truly inclusive in sport environments. We finish this paper with a proposed scale based on these propositions to develop an index that can be used to assess accessibility in stadium sport in any given region of the Global North.

\section{Theoretical framework: The social model of disability}

In this paper, we propose a social model of disability framework to examine this topic. This framework reconceptualises our understanding of disability away from the medical model discourse that has often shaped and dominated the world view of disability. This medical model positions disability as an individual concern of the "victim", where the focus is on the individual's functional and psychological losses arising from their impairment (Oliver, 1990; Darcy and Pegg, 2011; Small and Darcy, 2011). To challenge this dominant perspective, the social model argues that it is societal practices that transform an individual's impairment (embodiment) into a socially constructed disability. The social model focuses on the barriers that transform a person's impairment into socially constructed 'disability' that constrains social participation and, hence, citizenship of PwD. By using the social model our attention is focused on the disabling environment and the social attitudes that reinforce this. This social model focus can lead to the creation of more accessible and inclusive environments and 
challenges the hostile social attitudes present within institutions, procedures and protocols facing our identity group everyday (Barnes and Mercer, 2003).

Despite the promise of emancipation through the social model approach, the complexity of impairment/disability leads to two shortcomings of the social model. The first is that despite placing the individual at the centre of the model, their personal experience of impairment is overlooked because of the model focuses primarily on overthrowing societal constraints. This, critics argue makes the model overly socialised (Shakespeare, 2006; Terzi, 2004). In addition, an emphasis on the structural barriers that shape the relationship between the body and disability ignores experiences of impairment, which can vary significantly between individuals even though there are major commonalities in understanding access provisions between those with mobility, vision, hearing, cognitive, mental health, and other impairments (Hughes and Patterson, 1997; Terzi, 2004). To address these limitations, Shakespeare and Watson (2001) propose an embodied ontology which adds complexity to the social model. As a result, impairment is considered a central component and along with disability, both exist as fluid concepts that are seen as more or less relevant at different places and times. This embodied ontology breaks the dualism of agency and structure adding a corporeal dimension which sees the body as both socially constructed and physically experienced. Therefore, our reading of the social model is that disability is not just a function of an impairment but as an outcome of the interaction of impairment and the social environment, and the individual's embodied experience and their "impairment effects" (e.g., fatigue, temperature control, etc.). As such, we take direction from feminist disability theorists to ensure that the individual and their embodiment is not lost in understanding the social construction of disability within sport's socially constructed environment, procedures and protocols (Thomas, 1999, 2004).

The United Nations Convention on the Rights of Persons with Disabilities (CRPwD) (UN, 2006), widely recognised as the first international binding human rights treaty of the $21^{\text {st }}$ century, details the rights of PwD and sets out suggestions for its implementation through legislation, policy, and administrative measures. Relevant for this paper, Article 30 of this global convention enshrines the rights of citizens' access to take part in a cultural life "on an equal basis with others" (UN, 2006, online). Participation in cultural activities such as recreation, leisure, the arts, tourism, and sport enrich lives and provides multiple avenues for an individual's choice and freedoms of expression. The Convention is based on social model 
conceptualisations of disability and reinforces disability discrimination policies and legislation in many member countries. Additionally, Article 9 of the Convention, sets down the broad scope of accessibility, which traverses the "physical environment to transportation to information and communication, including information communication technologies and systems, and to other facilities and services open or provided to the public in both urban and in rural areas". Nevertheless, more than fifteen years since the United Nations passed this legal framework, over a hundred nations have implemented disability legislation around the world and have consolidated accessibility and universal design in the development of standards and guidelines (Darcy and Pegg, 2011; Darcy, 2017). Despite an extensive volume of disability and accessibility legislation at international level, building regulations and technical guidelines for the planning and management for venues and events, PwD still continue to face grave disadvantages to participate on an equal basis with others in recreational, leisure, tourism and sporting activities, including football. The theoretical underpinning of the social model of disability and these UN principles forms the lens by which we present this research study.

\section{Methodology}

Rapid review methodologies seek to improve the disconnect between research and decision making (Arskey and O'Malley, 2005; Haby et al., 2016). The importance of this study is in determining the unique challenges that SwD and older spectators face when accessing sporting stadia. As such, the authors conducted a rapid review to identify relevant studies that have examined the experiences of spectators with disabilities and the accessibility of sporting stadia and events. The protocol documented the search terms to be used (stadium, disability, spectator, and accessibility - these terms were truncated to include all forms of the 'root word' such as stadium, stadia, access, accessible, accessibility, disability, disabilities, disabled, spectator, spectators, spectatorship) and the three databases searched (Business Source Complete, Web of Science, Sport Discus) along with a manual search of peerreviewed publications known to the authors. The protocol outlined the inclusion criteria [any peer reviewed study in English or Spanish, using qualitative, quantitative or mixed methods theoretical advances and commentaries were included as long as they had been peer reviewed, published from January 1996 to March 2021, when the review was conducted; and the exclusion criteria (non-English or Spanish language, editorials, letters, protocols, interventions or experiments); the types of participants included both PwD and policy makers and managers of the various stadia and events. 
Given the rapid nature of this review, the initial screening exercise involved reading the records' titles and abstract to remove the records that were duplicated or obviously irrelevant. As such from the initial screening of title and abstracts $(n=425)$ were reduced into a final set of studies $(n=43)$ which met the relevancy criteria and were included for full data extraction (Figure 1). Upon full data extraction nine papers were cut from the sample due to quality and relevance issues with the paper's findings.

Insert Figure 1 about here.

\section{Figure 1: PRISMA Diagram for rapid review / study selection flow chart.}

Limitations in this approach include excluding books and book chapters which would have been covered in a broader scoping study. Studies were also limited to English or Spanish language that the research team had expertise in. This only which reduced the potential for coverage of certain geographic regions, as such only one study came from outside the global north nations.

\section{Results}

From the database search, a total of 467 items were identified and deemed suitable for screening this included thirteen sources were generated because of manual searches. Upon the removal of duplicates $(n=42)$ title/abstract screening was carried out on the remaining along with the implementation of the screening criteria (full text, English or Spanish, peer reviewed academic journal) resulting in a total of forty-three articles being retrieved. During the eligibility check each author read through each of these documents and decisions to include and exclude were made by consensus (no decisions were split two votes to two avoiding the need for a further step). After these full text assessments, a total of thirty-four articles were selected in the final sample for qualitative synthesis. Prior to the presentation of this synthesis, it is important to highlight the frequency of publications over time and the geographical regions from which the research has been generated. Table 1 lists the thirty-four reviews in chronological order since 1998 to now, geographical area, together with their key features, and an overview of these works.

Insert Table 1 around here 
Figure 2 identifies the frequency of these synthesised publications over time, note this does not include all 467 items from the entire review. The first papers in the final sample appeared in 1998 with a further eight publications over the next 14 years, six of these being in the sport studies literature. It was not until 2013 that this topic featured in the sport management literature but from that point the number of papers to be published over the previous nine years has increased threefold. Yet it remains an obscure topic within the field, with on average one publication each year in both sport management and wider sport studies journals. As PwD make up approximately $15 \%$ of the world's population, greater attention is therefore required on this area from within the sport management literature.

Insert Figure 2 about here.

Figure 3 highlights the wider region where each study took place. It should be noted that some studies included more than one site and the suite of studies from Misener et al. (2015), amongst others, involve comparative analysis from Canada and Scotland. Nevertheless Europe (51.3\%) and North America (43.6\%) dominate the research settings with Australasia's four studies at $10.3 \%$. Only one study comes from the nations of the Global South, with Yazigi et al.'s (2015) analysis set in Brazil in the lead up to the 2014 Men's FIFA Football World Cup. A clear need for research from outside the Global North is apparent.

Insert Figure 3 about here.

\section{The methodological approaches of the sample}

Most papers used overwhelmingly qualitative explorations of the field to explore issues of access. The use of document analysis featured in just over half of the publications in this sample $(n=18,53 \%)$. These were frequently used to provide historical context and the official perspective of the organisations under examination and as a way of informing the development of interview schedules. In part these informed a series of general reviews (Brown, 2020; Conrad, 1998; Darcy and Harris, 2003; Dickson et al., 2011; Hums et al., 2016; Kurak, 2001; Penfold and Kitchin, 2020; Petersen and Judge, 2014), while systematic reviews (Dickson et al., 2017a) were also included in the sample which provide important devices for taking stock of the wider context of accessibility from legal and operational viewpoints. In addition to these, there were three papers within the sample that specifically 
developed theoretical/conceptual notions about accessibility through their analysis of data (Dickson et al., 2016; Downs and Seifried, 2021; Misener, 2015) and it is within these series of studies that we situate our framework.

Other common data collection tools included interviews and observations, much of this being implemented in the field. Much of the work sought to explore access on-site and, in some cases, involving PwD in these on-site evaluations (Panchanathan et al., 2019; Yazigi et al., 2015) or post experience feedback sessions (Grady and James, 2013). The collection of onsite data through general observations (Darcy, 2003; Grady and James, 2013; Mahoney and McMillen, 2011; McGillivray et al., 2018; Misener et al., 2015, 2020; Paramio-Salcines and Kitchin, 2013; Paramio-Salcines et al., 2014), through photo elicitation of accessibility from the researcher's (Dickson et al., 2016; Garcia et al., 2017), or SwD's perspective (Southby, 2013) were also common field methods used to reveal a richer experience of accessibility.

Less frequent were survey questionnaire methods, but three in this sample used surveys to explore various accessibility issues involving the London 2012 Olympic and Paralympic Games for both athletes with disability (Bamford and Dehe, 2014) and volunteers with disability (Darcy et al., 2014; Dickson et al., 2017b). This survey method was also used in an exploration of sports tourists with disability to identify their preferences, experiences, and barriers to access (Yfantidou et al., 2018).

\section{The involvement of PwD in the research}

Within the sample, thirteen papers (38\%) drew explicitly on the experiences of PwD in spectating live sport. Research focused on the experience of people with mobility impairments (Grady and James, 2013; Sanford and Connell, 1998; Yazigi et al., 2015; Yfantidou et al., 2018), on spectators with learning difficulties (Grünke et al., 2016; Southby, 2013), and people with a vision impairment (Panchanathan et al., 2019). Additionally, research by Darcy et al. (2014) and Dickson et al. (2017b) focused on pan disability which included mobility, vision, Deaf/Hearing and those who identify with disability but do not avail of access requirements. Two papers (Paramio et al., 2008; Paramio-Salcines and Kitchin, 2013) explored the experiences of Disability Liaison Officers (DLOs) who were members of the disability community, however the job role was the inclusion criteria in their sampling, not that they were a person with a disability. In two further papers, the disability type of the individual in the study was not presented (Bamford and Dehe, 2014; Garcia et al., 
2017). Overall, this focus of the experiences of PwD equates to roughly $2 / 5$ of the total sample, thus providing only a minority of perspectives from $\mathrm{PwD}$ themselves. It should be noted however that in the nine papers exploring the perspectives of managers, there was no indication whether or not those managers were from the disability community. This should also be noted for the authors of this sample of papers, as based on personal connections and knowledge of the discipline four authors appearing on nine papers are people with disability. Nevertheless, sport management academia should prioritise the perspectives of those who have experience of disability in both the formulation of, and participation in further research.

\section{Discussion}

Narrative synthesis was used to identify key themes across studies from the included articles in order to address the first research question (What does the peer reviewed evidence tell us about SwD and the accessibility of sporting stadia?). All eligible studies were read and reread by the authorship team which is more than appropriate for a rapid review protocol, which usually involves only the lead researcher. Once identified, sample groups, key areas of focus, themes, and methodologies were compared between studies.

\section{Emergent themes}

\section{Investigations into legislative compliance}

Under the UN CRPWD, national legislation (for example, the Americans with Disabilities Act (ADA)), building codes, and the interpretation of various technical guidance [see the International Paralympic Committee's Accessibility Guide for host cities (IPC, 2015), or the Accessible Stadia Guide (SGSA, 2015) for English football stadia], there are numerous layers of guidelines that sport managers need to be cognizant of. Whether or not sports stadia or major events have met their accessibility commitments under these layers of guidance is a feature of a number of these studies.

Kurak's (2001) research focused on enhanced lines of sight for individuals in wheelchairs at sports stadia - which is important so they can enjoy an unrestricted view of the game from their chair. His review of three court cases found that this specific issue was not well covered by the ADA, and confusion about its implementation existed. This reflected the confusion inherent in the writing of the act that was exposed by Conrad (1998) in his earlier study and 
the ability, or lack of the federal government to promote of the ADA. Paramio-Salcines and Kitchin (2013) revealed that within the European Union, differences in national legislation brought about significant differences in the implementation of accessibility of clubs playing in the same European competition. Similar to the findings of Sanford and Connell (1998) in the United States, Paramio-Salcines and Kitchin revealed practices valued by the clubs that still do not necessarily comply with national legislation. Recent research has also commented on the risks of misinterpretation building safety guidelines in the return of disabled fans to sporting stadia in English football (Brown, 2020; Penfold and Kitchin, 2020). This grey area created by the COVID-19 pandemic is open at the possibility for breaches of the English Equality Act 2010 around ableist assumptions about the nature of vulnerability.

In a more positive vein, Hums et al., (2016) argue that the ADA has provided individuals with disabilities greater access to sport. It has raised the profile of Universal Design principles and the authors provide examples of this management strategy in sport environments. Additionally, Mahoney and McMillen (2011), after examined the Dallas Cowboys Mobility Assistance Program from the perspective of its compliance with ADA regulations, found the programme went beyond the minimum standards of what as expected yet, and still there were areas of improvement identified.

A limitation of this strand of studies is that they are overly focused on mobility impairments within the spectator space, which exposes two issues. The first is that while physical disability is the first category of disability it is still only one category and as such excludes many voices. Second, the focus on the spectator space implies the accessibility of other facilities such as locker rooms or spaces used by employees (Sanford and Connell, 1998, p. 66) are excluded from analysis and limits our understanding of the holistic perspective of accessibility of sports stadia.

\section{A focus on resource enhancement}

One of the features of sport and management journals is the provision of practical recommendations for managers operating in the field. A number of these studies have attempted to address this by generating recommendations based on their analysis. Both physical and human resources have been identified as areas of improvement. Examples of these include the use of technology to enhance the match day experience (Panchanathan et al., 2019), the layout and potential reconfiguration of seating (Kurak, 2001; Sanford and 
Connell, 1998) which could also enhance lines of sight (Conrad, 1998; Grady and James, 2013), better signage and wayfaring information (Grady and James, 2013; Malhoney and McMillen, 2011).

Grady and James' (2013) findings about the salience of needs expose some flaws in the overt focus on physical resources alone. As the spectator negotiates certain barriers in accessing the venue, their service requirements change. As such, a focus on physical resources is not only just the start (McPherson et al., 2014) but alterations to these resources without considering the impact on the customer experience is unwise. For example, Kurak (2001) recommends that management can do several things to enhance sight lines for SwD, including using removable seats in front of wheelchair spaces, not selling the seats in front of patrons who required wheelchair space, or policies to prevent other patrons from standing during play and blocking sight lines. All these recommendations appear in the first instance to prevent $\mathrm{SwD}$ being inconvenienced. However, enacting these ideas will alter the experience for any SwD by essentially isolating them to a position where they are surrounded by no one else and at the same time preventing any of their non-disabled friends from sitting with them. As such individual resource items should not be altered in isolation but the wider experience must be considered. This relates to the recent focus on transformative service research (Anderson et al., 2013) that has emphasised the need for a collaborative, holistic approach, to better understand accessibility across the wider stadium experience, including transport, accommodation and venues within a physical destination (Dickson et al., 2017).

An important part of this wider experience and one which several studies have provided recommendations on is human resources. Indeed, Sanford and Connell (1998) go as far to suggest that "management practices and attitudes are arguably the most important issue in the overall experience of people with disabilities, regardless of the physical accessibility of a facility" (p. 85). Evidence suggests that staff and managerial attitudes form substantial, yet intangible barriers that restrict the access of SwD (Grady and James, 2013; Misener et al., 2015; Paramio-Salcines and Kitchin, 2013; Sanford and Connell, 1998). For example, Mahoney and McMillen (2011) recommended the appointment of dedicated staff and coordinators for SwD that would not be shared with other patrons. They also recommended that services should be provided on request, further reinforcing the notion that we should not foist assistance on spectators just because they may experience disability, reinforcing ideas on consumer choice. Research has conceived and demonstrated the importance of human 
resources as change agents to champion accessibility within stadia (Misener, 2015; ParamioSalcines and Kitchin, 2013). Paramio-Salcines and Kitchin revealed that a coordinated network of Disability Liaison Officers (DLOs) across the German Bundesliga and Bundesliga 2 created a strong platform for accessibility.

A small number of studies underpinned the need for clear information and good communications to assist accessibility (Garcia et al., 2017; Pate et al., 2015; Yazigi et al., 2015). This intellectual resource is vital as it is in many cases the very first interaction a customer has with any business. When this information is lacking it creates service issues for sport and event managers, as seen in Bamford and Dehe's (2014) study on athletes with disabilities at the London 2012 Summer Paralympic Games, while the lack of pre-game information was not seen as critical to the overall service quality of the event it scored the lowest on all the performance measures.

What is missing from the sample are recommendations for increased financial resources, which in itself is an interesting finding. Perhaps by recommending new physical, human, and intellectual resources, the authors are implicitly seeking to augment financial resource. Based on the above analysis, it is pertinent the increased financial resources underpin the training of staff and managers in disability awareness training, while the creation of new posts, like the creation of the role of Disability Access Officers (DLOs) in European football could be one critical step in the right direction.

\section{Moving beyond the stadium experience}

Just under half of the total sample ( $\mathrm{n}=15,44 \%)$ set their focus within the sport stadium environment. As discussed previously, this was to explore the legal and operational implications of managerial decisions regarding accessibility. While greater attention is placed on the stadium, not just in revenue maximisation opportunities, but also in its role and importance of as a historical and cultural part of its community (Downs and Seifried, 2021; Paramio et al., 2008) an awareness of the community/identity is essential. While this setting is under the relative control of the sport manager, more recent studies in the sample demonstrate a trend towards studies focusing on the sport manager's role in managing major sporting events accessible social legacies and widening our attention on the complete end-toend journeys SwD and older spectators undertake in accessing sport. An example of both types of broadening responsibility rests with the work of Dickson et al., (2016). They 
explored the fan zones (a public access space which is an extension of the stadium, see Ludvigsen, 2021) in the 2015 FIFA Women's World Cup in Canada. Not only did their study apply the concepts of transformative service research and service blueprinting to this major event but they used them as a tool for analysing performance for SwD with different disability types, across the full visitor journey from "planning, travel, entry/exit, activity participation, viewing and [the] use of facilities" (p. 551). They reveal the level of detail that stadium and event managers require to meet the requirements of SwD before, during, and after the event.

Accessibility as a social legacy of major sport events: Major/mega events are often accompanied by rhetoric about the event's lasting impact and progressive opportunities for the region that hosts it (McGillivray et al., 2018). A group of publications led by scholars such as Laura Misener and Tracey Dickson have set about developing frameworks to allow these promises to be examined and tested. Misener et al. (2020) explored the formation of cross sector partnerships to create opportunities for accessible social legacies and long -term opportunities for disability sport development as a result of the Toronto 2015 Games. They argue that an event of this scale provided a window of opportunities for stakeholders to come together and develop structures in resource-scarce areas like disability sport. Despite these positive outcomes, other studies demonstrated that improvements to city infrastructure were either inaccessible to marginalised groups (McPherson et al., 2017) or favouring stakeholders who already possessed sufficient stocks of capital to navigate the social spaces in the event aftermath (McGillivray et al., 2018). A major limitation they identify in this rhetoric of social legacy is over who has control over the long-term impact of the games which determines that a community asset like an accessible facility is only a starting point for legacy, yet it is "the revenue resources to program, enable transport, and maintain staff training to support adaptive sport [that] is beyond the responsibility of Games organizers" (McPherson et al., 2017, p. 196) and in the remit of city planners and where relevant, government departments of sport and recreation.

Understanding the whole journey: Garcia et al. (2017) argued that it was time to move beyond the status quo of access and information as the basis of our service offering for SwD. This notion aligns with a range of papers found within our sample that consider the whole customer experience, rather than limiting our view to what occurs within the built environment. A broader understanding of access and inclusion for PwD in sports stadia and 
major events, even above and beyond the ideas developed by Dickson et al. (2016) that includes planning and policy, managerial and staff attitudes that include an understanding of the salience of needs, working with stakeholders and developing strategic partnerships, physical resources are all part of the discussion. There are these concepts derived from the above review of evidence that are needed to develop future research and practice.

\section{Propositions for sport management research and practice}

From the discussion above, both the social legacy of major sporting events in creating accessible environments and the wider impact of stadium accessibility require further attention. The breadth of our review demonstrates that the practice of planning and/or managing for a post-event legacy for accessible sport and that the practice of managing the community around the sporting stadium are different research tracks. Given the aims of this paper, we seek to focus on the latter in managing the stadium and community context to facilitate the entire accessible journey sequence. This paper will now conclude with the development of two propositions that develop both a research agenda and practical applications and demonstrating how can this information develop propositions for assessing a Stadium Accessibility Scale (SAS)?

Accessible End-to-End Journeys: When reviewing the concept of accessibility within the built environment of sport, Paramio et al., (2012) and Paramio-Salcines et al., (2018) established the concept of the HOPES framework that represented a journey sequence model of the athlete/official/customer when attending sporting events and stadia. This HOPES framework sets out five stages involved in the stadium experience: Hopes (Pre-experience); On the way to the stadium ( $2^{\text {nd }}$ phase of the pre-experience); Participating in the experience (The experience itself); Enjoy the journey home and Sharing (post-experience). The management of the needs and experiences of SwD and older supporters should cover all aspects of accessibility, including rational (regulations) and emotional aspects as part of what Rawson et al., (2013) describe as the "customer's end to end journey”. By doing this, the HOPES model is said to have the potential for understanding all factors that clubs need to supply in each phase to provide equal opportunities to access to facilities and services and quality of experience to SwD and older fans attending events at stadia. Underpinning this framework is the "notion that designing accessible and inclusive sport environments can have economic, social and operational benefits and implicitly benefits the whole of society" (Paramio-Salcines et al., 2018, p. 534). 
Insert Figure 4 about here

\section{Figure 4. Overview of the five phases of the HOPES model}

We argue that future research on accessibility in sports stadia align to this broader approach to the customer experience, and while we acknowledge that many aspects lay outside the traditional remit of the stadium/sport manager the possibilities lay in strategic partnership between sport and its wider communities (Misener et al., 2020).

\section{Proposition 1: Encourage further research aligned to the HOPES framework}

Developing a performance management system to assess stadium accessibility: The first step in the process of developing an accessibility scale will involve combining the analysis from the rapid review, previous academic literature and from practitioner guidelines on accessibility at sports venues and stadia (Darcy, 2010; Veal and Darcy, 2014). This included the audit of facilities developed by the National Association of Disabled Supporters in the UK (NADS, now known as 'Level Playing Field'): this audit was completed with the input of SwD and 'set in motion a process of real representation of the needs of disabled supporters' (NADS, 1999, p. 1). Their survey focused on six sections: a) general information (address and contact details of every club; disabled supporter club and directions); b) pre-travelling information; c) travel arrangements; d) facilities and services within stadium, including places and positions at the stadium for wheelchair users, fans with visually impairments, fans who are hard of hearing and ambulant disabled supporters; d) toilets and catering; e) leaving the ground amongst other items.

In the follow up study in 2003, NADS developed an access checklist with 87 items, including among the following phases (first contact/tickets, 13 items); (arrival, 14 items), access to the stadium (5 items) and disability spectator viewing (Football Stadia Improvement Fund, 2004). Stemming from the 2003 NADS's study framework, Paramio et al., (2012) conducted an exploratory analysis of the state of accessibility at a sample of stadia from elite league clubs in Germany, Spain, and England. This sample included seven stadia of EPL at the 2009-10 season and the new Wembley, seven stadia of the German Bundesliga at the same season and six top stadia of the Spanish Liga de Futbol Profesional. At that time, this 
comparative study used an holistic journey sequence approach, including five phases (anticipation, pre-travelling to the stadium, attending the event at the stadium, leaving the stadium and recollection). The emphasis of Paramio et al. 's study was on describing and quantifying the range of basic services and facilities offered by clubs for SwD (club name and web contact, date of stadia built and capacity, supply of seats for different types of SwD, percentage between capacity versus seats supplied and other accessible services). However, their study omitted any indicator to determine the quality of services and facilities for SwD which are important for the pre- and post-event phases of the HOPES framework.

More recent analysis on all EPL clubs was undertaken by the British disability-advocacy charity Revitalise. In 2015, they produced an Accessibility League table for football clubs in the English Premier League and the Football League Championship (Revitalise, 2015). Further guidance from the Bundesliga which incorporates standards for stadia and DAO in their clubs (Ackermann et al., 2019) was also used. Similarly, the Spanish LaLiga has only recently started to evaluate the level of accessibility at Primera and Segunda Division stadia (Paramio-Salcines et al., 2018). From previous studies in our sample, evidence proves that there are significant differences in complying with legislative, regulatory and guidelines at club's stadia of the main leagues that were established by the Accessible Stadia Guide and the Barrierefrei ins stadion. There is neither a common agreement about the provision of (minimum) seats for SwD, accessible toilets, or other facilities and amenities, nor a lack of standardised system of management of ticketing for fans with disabilities across Europe. Furthermore, some clubs have a long history of going 'above and beyond' the requirements set by legislation (Downs and Paramio-Salcines, 2013). Future research should develop and validate an accessibility league scale in order to refine the possible indicators situated within a HOPES framework and creating a reliable performance measurement system for improving accessibility in sport stadia.

\section{Proposition 2: Develop and validate a reliable Accessible Stadium Scale Performance Measurement System}

In developing any instrument to form the basis of a scale for performance measurement or an index of accessibility requires co-creation in the design process that brings together technical elements (construction and accessibility standards) with an understanding of the lived experience across disability type (mobility, hearing, vision, cognitive, neuro diverse and 
mental health). One of the tenants of social approaches to disability is the catch cry "Nothing about Us without Us" (Charlton, 2000) where people with disability have too often been the subject of research without being involved in actively shaping all stages of the research. Similarly, transformational services research is the most recent attempt to articulate the importance of understanding the position of disability within marketing research to make the outcomes of research more robust in providing practical solutions as an immediate focus rather than just theorising the importance of social change. While the language remains paternalistic ("vulnerable consumers") there is some recognition of creating improved social change outcomes. Similarly, those in academia have too often led the agenda without including people with disability as part of research teams. Further, there has been an explosion of papers that have examined the atrocious experience of academics with disability in academia (Yerbury and Yerbury, 2021). Sport management has seen a relative absence of an understanding of the lived experience and few scholars that identify as having disability actively engaged within research teams. Yet, we have seen a shift in studies on gender and sport where the importance of women has been championed and more recently the rise of First Nations scholars as lead researchers as opposed to nonindigenous researchers leading research teams. Disability studies theorists have given voice to the lived experience but most research on disability is still led by nondisabled researchers with very little involvement of researchers with disability or co-design processes put in place with the disability community. We hope to continue to contribute towards this change of hearing the lived experience, cocreating our research with the disability community, and championing a disability researcher as part of our team together with hiring research assistance with disability where possible. 


\section{References}

Ackermann, A., Krämer K., and Wurbs, D. (2019), National DAO Networks \& Structures in German Football, CAFE conference, Barcelona, Spain.

Anderson, L., Ostrom, A.L., Corus, C., Fisk, R.P., Gallan, A.S., Giraldo, M., Mende, M., Mulder, M., Rayburn, S.W., Rosenbaum, M.S. and Shirahada, K. (2013), "Transformative service research: An agenda for the future", Journal of Business Research, Vol. 66 No 8, pp.1203-1210.

Arksey, H. and O’Malley, L. (2005), "Scoping studies: towards a methodological framework", International Journal of Social Research Methodology, Vol. 8 No. 1, pp. 19-32.

Australian Human Rights Commission (AHRC) (2021), Complaint cases conciliation register, AHRC, Sydney.

Bamford, D. and Dehe, B. (2016), "Service quality at the London 2012 games - a Paralympics athletes survey", International Journal of Quality \& Reliability Management, Vol. 33 No. 2, pp. 142-159.

Barnes, C, and Mercer, G. (2003), Disability, Cambridge, Polity Press.

Brown, C. (2020), "Football must not forget its inclusive responsibilities in the rush to get fans back into stadiums", Managing Sport and Leisure, https://doi.org/10.1080/23750472.2020.1858147

Buhalis, D. and Darcy, S. (2011), Accessible tourism: Concepts and cases, Channel View Publications Ltd., Bristol.

Charlton, J. I. (2000), Nothing about us without us: Disability oppression and empowerment. University of California Press.

Conrad, M.A. (1998), "Wheeling through rough terrain - the legal roadblocks of disabled access in sports arenas", Marquette Sports Law Review, Vol. 8 No. 2, pp. 263-287.

Culture, Media and Sport Select Committee (2016), Accessibility of sports stadia, House of Commons, London.

Culture, Media and Sport Select Committee (2017), Accessibility of sports stadia. Fifth report of session 2016-17. House of Commons, London, available at https://publications.parliament.uk/pa/cm201617/cmselect/cmcumeds/62/62.pdf (Accessed, 7 January 2019).

Darcy, S. (2003), "The politics of disability and access: The Sydney 2000 Games experience", Disability \& Society, Vol. 18, pp. 737-757.

Darcy, S. (2010), "Inherent complexity: Disability, accessible tourism and accommodation information preferences", Tourism Management, Vol. 31, pp. 816-826.

Darcy, S. (2017). "Accessibility as a key management component of the Paralympics", Darcy, S. Frawley, S. and Adair D. (Eds), Managing the Paralympics. Palgrave Macmillan, Basingstoke, Hampshire, pp. 47-90.

Darcy, S. and Harris, R. (2003), "Inclusive and accessible special event planning: An Australian perspective”, Event Management, Vol. 8, pp. 39-47. 
Darcy, S. and Pegg, S. (2011), "Towards strategic intent: Perceptions of disability service provision amongst hotel accommodation managers," International Journal of Hospitality Management, Vol. 30, 468-476.

Darcy, S., Frawley, S., and Adair, A. (2017), Managing the Paralympics, Palgrave, London.

Dickson, T., Benson, A. and Blackman, D. (2011), "Developing a framework for evaluating Olympic and Paralympic legacies", Journal of Sport \& Tourism, Vol. 16 No. 4, pp. 285-302.

Dickson, T.J., Darcy, S. and Benson, A. (2017b), "Volunteers with disabilities at the London 2012 Olympic and Paralympic Games: Who, why, and will they do it again?", Event Management, Vol. 21 No. 3, pp. 301-318.

Dickson, T.J., Darcy, S., Johns, R. and Pentifallo, C. (2016), "Inclusive by design: transformative services and sport-event accessibility", Service Industries Journal, Vol. 36 No. 11-12, pp. 532-555.

Dickson, T.J., Misener, L. and Darcy, S. (2017a), "Enhancing destination competitiveness through disability sport event legacies", International Journal of Contemporary Hospitality Management, Vol. 29 No. 3, pp. 924-946.

Downs, B.J. and Seifried, C.S. (2021), "Modernization and multipurpose arenas: providing context for tomorrow", Sport, Business and Management: An International Journal, Vol. 11 No. 4, pp. 384-404.

Downs, P., and Paramio-Salcines, J.L. (2013), "Incorporating accessibility and disability in the Manchester United culture and organization as part of their CSR policies", Paramio Salcines, J. L., Babiak, K. and Walters, G. (Eds), Routledge Handbook of Sport and Corporate Social Responsibility, Routledge, Abingdon, pp. 135-146.

Equality and Human Rights Commission (EHRC) (2017), Being disabled in Britain. A Journey less equal, EHRC, London. Available at: https://www.equalityhumanrights.com/sites/default/files/being-disabled-in-britain.pdf (accessed 21st May 2021).

Football Stadia Improvement Fund, (2004), Accessible stadia, London, Football Stadia Improvement Fund and Football Licensing Authority.

Garcia, B., (2017), "Football and governance", Hughson, J., Moore, K., Spaaij. R., and Maguire, J., (Eds), Routledge Handbook of Football Studies, Routledge, Abingdon, pp. 99-110.

Garcia, B., de Wolff, M., Welford, J. and Smith, B. (2017), "Facilitating inclusivity and broadening understandings of access at football clubs: the role of disabled supporter associations", European Sport Management Quarterly, Vol. 17 No. 2, pp. 226-243.

Grady, J. and James, J.D. (2013), "Understanding the needs of spectators with disabilities attending sporting events", Journal of Venue \& Event Management, Vol. 4 No. 2, pp. 48-62.

Grünke, M., Ropohl, B. and Semmling, H. (2016), "Facilitating social inclusion of young adults with learning disorders through football fandom", Insights into Learning Disabilities, Vol. 13, pp. 103-115.

Haby, M.M., Chapman, E., Clark, R., Barreto, J., Reveiz, L. and Lavis, J.N. (2016), "What are the best methodologies for rapid reviews of the research evidence for evidence- 
informed decision making in health policy and practice: a rapid review", Health Research Policy and Systems, Vol. 14 No. 1, pp. 83-7.

Hughes, B., and Patterson, K. (1997), "The social model of disability and the disappearing body: Towards a sociology of impairment", Disability \& Society, Vol. 12, pp. 325340.

Hums, M. A., Schmidt, S. H., Novak, A. and Wolff, E. A. (2016), "Universal design: Moving the Americans with Disabilities Act from access to inclusion", Journal of Legal Aspects of Sport, Vol. 26 No. 1, pp. 36-51.

Kurack, J. (2001), "Standing in front of the disabled: judicial uncertainty over enhanced sightlines in sports arenas", Villanova Sports \& Entertainment Law Journal, Vol. 8 No. 1, pp. 161-188.

International Paralympic Committee (IPC) (2015), Accessibility Guide, available at: https://www.paralympic.org/sites/default/files/document/160307102314920_IPC+Acc essibility + Guide.pdf

Ludvigsen, Y (2021), "Between security and festivity: the case of fan zones." International review for the Sociology of Sport, Vol. 56 No. 2, pp. 233-251.

Mahoney, M. and McMillen, J. (2011), "Cowboys stadium mobility assist program: Accessible routes and the Americans with Disabilities Act accessibility guidelines", Journal of Legal Aspects of Sport, Vol. 21 No. 1, pp. 101-115.

McGillivray, D., McPherson, G. and Misener, L. (2018), "Major sporting events and geographies of disability", Urban Geography, Vol. 39 No. 3, pp. 329-344.

McPherson, G., Misener, L., McGillivray, D. and Legg, D. (2017), "Creating public value through Parasport events", Event Management, Vol. 21 No. 2, pp. 185-199.

Misener, L. (2015), "Leveraging parasport events for community participation: development of a theoretical framework", European Sport Management Quarterly, Vol. 15 No. 1, pp. 132-153.

Misener, L., Lu, L.D. and Carlisi, R. (2020), "Leveraging events to develop collaborative partnerships: Examining the formation and collaborative dynamics of the Ontario Parasport legacy group", Journal of Sport Management, Vol. 34 No. 5, pp. 447-461.

Misener, L., McGillivray, D., McPherson, G. and Legg, D. (2015), "Leveraging parasport events for sustainable community participation: The Glasgow 2014 Commonwealth Games", Annals of Leisure Research, Vol. 18 No. 4, pp. 450-469.

NADS- National Association Disabled Supporters (1999), NADS match-day audit-informal questionnaire/report. NADS, Football Foundation, England.

Oliver, M. (1990). The politics of disablement, MacMillan, Basingstoke.

Panchanathan, S., Mcdaniel, T., Tadayon, R., Rukkila, A. and Venkateswara, H. (2019), "Smart stadia as testbeds for smart cities: Enriching fan experiences and improving accessibility", International Conference on Computing, Networking and Communications. ICNC.

Paramio Salcines, J.L., Grady, J. and Downs, P. (2014), "Growing the football game: the increasing economic and social relevance of older fans and those with disabilities in the European football industry", Sport in Society, Vol. 15 No. 6, pp. 864-882. 
Paramio, J.L., Buraimo, B. and Campos, C. (2008), "From modern to postmodern: The development of football stadia in Europe", Sport in Society, Vol. 11 No. 5, pp. $517-$ 534.

Paramio-Salcines, J. and Kitchin, P.J. (2013), "Institutional perspectives on the implementation of disability legislation and services for spectators with disabilities in European professional football", Sport Management Review, Vol. 16 No. 3, pp. 337348.

Paramio Salcines, J.L., Downs, P. and Grady, J. (2016), "Football and its communities: The celebration of Manchester United's Ability Suite”, Soccer and Society, Vol. 17 No. 5 , pp. $770-791$.

Paramio-Salcines, J.L. and Llopis-Goig, R. (2019), "Structures and policies at the main European football leagues", Chadwick, S., Parnell, D. Widdop P., and Anagnostopoulos C. (Eds), Routledge Handbook of Football Business and Management, Routledge, Abingdon, pp. 33-43.

Pate, J., Bemiller, J. and Hardin, R. (2010), "Reserved: Best practices for on-campus football parking for people with physical disabilities", Journal of Venue \& Event Management, Vol. 2, pp. 1-13.

Penfold, C. and Kitchin, P.J. (2020), "Will it ever be completely safe to be in a crowd again? the return of disabled supporters to football stadiums during COVID-19", Managing Sport and Leisure, Vol. ahead-of-print No. ahead-of-print, pp. 1-10. https://doi.org/10.1080/23750472.2020.1850325

Petersen, J.C. and Judge, L.W. (2014), "Sport spectator seating: ADA accessibility in existing facilities", JOPERD: The Journal of Physical Education, Recreation \& Dance, Vol. 85 No. 7, pp. 42-43.

Revitalise (2015), "Footie4All. An accessibility survey of the UK's Premier League stadiums”, available at http://revitalise.org.uk/wpcontent/uploads/2015/08/Table_FINAL.pdf (accessed 15 Feb 2019).

Sanford, J.A. and Connell, B.R. (1998), "Accessible seating in stadiums and arenas", Journal of Urban Technology, Vol. 5 No. 1, pp. 65-86.

Shakespeare, N. (2006), Disability rights and wrongs, Oxon, Routledge.

Shakespeare, T. and Watson, N. (2001), "The social model of disability: An outdated ideology?", Barnartt, S.N. and Altman, B.M. (Ed.) Exploring theories and expanding methodologies: Where we are and where we need to go (Research in Social Science and Disability, Vol. 2), Emerald Group Publishing Limited, Bingley, pp. 9-28.

Small, J., and Darcy, S. (2011), "Understanding tourist experience through embodiment: the contribution of critical tourism and disability studies", Buhalis, D. and Darcy, S. (Eds), Accessible tourism and cases, Channel View Publications Ltd, Bristol, UK, pp. 73-97.

Southby, K. (2013), "Social inclusion through football fandom: opportunities for learningdisabled people", Sport in Society, Vol. 16 No. 10, pp. 1386-1403.

SGSA- Sports Grounds Safety Authority (2015), Accessible Stadia supplementary guidance. SGSA, London.

Terzi, L. (2004), "The social model of disability: A philosophical critique”, Journal of Applied Philosophy, Vol., 2, no. 2, pp. 141-157. 
Thomas, C. (1999), Female forms: Experiencing and understanding disability, Open University Press, Buckingham.

Thomas, C. (2004), "Disability and impairment", Swain, J. French, S. Barnes C., and Thomas C. (Eds). Disabling Barriers-Enabling Environments, Sage, London, pp. 21- 28.

UN- United Nations (2006). "Convention of the rights of persons with disabilities (CRPWD)". available at https://www.un.org/development/desa/disabilities/convention-on-the-rights-of persons-with-disabilities.html (Accessed 21 May 2021)

Veal, A. and Darcy, S. (2014), Research methods in sport studies and sport management. A practical guide, Routledge, London.

Yazigi, S., Resende, A.E. and Yazigi, R. (2015), "Accessibility in soccer stadiums: Infrastructure and organization in support of people with reduced mobility - A use analysis", 6th International Conference on Applied Human Factors and Ergonomics (AHFE 2015) and the Affiliated Conferences. AHFE.

Yerbury, J. J., and Yerbury, R. M. (2021), "Disabled in academia: to be or not to be, that is the question", Trends in Neurosciences. Vol. ahead-of-print, No. ahead-of-print, pp. $1-3$.

Yfantidou, G., Zioumbiloudi, A. and Balaska, P. (2018), "Sport tourists with disabilities accessible tourism, accommodation, recreation and sport in Greece", Hellenic Journal of Sport \& Recreation Management, Vol. 15 No. 2, pp. 26-39. 